\title{
Attitude to counseling and testing for HIV and knowledge about prevention of mother to child transmission of HIV in men accompanying antenatal attendees at a tertiary care hospital in South India
}

\author{
Nivedita Krishnamoorthy*, Fatima Shanthini Navis
}

Department of Obstetrics, Sree Manakula Vinayagar Medical College and Hospital, Kalitheerthalkuppam, Puducherry, India

Received: 13 February 2021

Revised: 06 April 2021

Accepted: 09 April 2021

*Correspondence:

Dr. Nivedita Krishnamoorthy,

E-mail: niveog91@yahoo.com

Copyright: (C) the author(s), publisher and licensee Medip Academy. This is an open-access article distributed under the terms of the Creative Commons Attribution Non-Commercial License, which permits unrestricted non-commercial use, distribution, and reproduction in any medium, provided the original work is properly cited.

\begin{abstract}
Background: Parent to child transmission is the second most common route of transmission of HIV in India contributing to $5 \%$ of new infections. This is due to underutilization of the components of PPTCT among pregnant women. As male partners remain the main decision makers in the family and influence their wife's behaviour, poor awareness and negative attitude of men towards testing and treatment of HIV is a hindering factor in the successful implementation of the program. Therefore this study was carried out to study the awareness of men regarding HIV and PPTCT and also to assess their attitude towards testing and treatment in an antenatal clinic setting.

Methods: This is a cross sectional descriptive institution based study conducted in Sri Manakula Vinayagar Medical College and Hospital, Puducherry, India. The study participants were men who accompanied their pregnant wife to the antenatal clinic. A pretested, predesigned questionnaire was used as the survey tool to assess the knowledge of these men about PPTCT services and also to assess their attitude towards HIV testing during pregnancy. The collected data was entered in SPSS and analyzed using descriptive statistics.

Results: Among participants only $68 \%$ were aware that a HIV positive mother could transmit infection to her baby and more than half of the participants were not aware that breast feeding could cause vertical transmission. Nearly $39 \%$ of the participants were not aware that mother to child transmission can be curtailed by giving ART during pregnancy. Acceptance for HIV testing was fairly good even before pretest counseling to the extent of $88.6 \%$ of the participants. Among the participants who did not want to get tested for HIV, 52.9\% assumed that their HIV status will be the same as that of their wife whereas $29.4 \%$ said that they were not comfortable undergoing the test along with their wife.

Conclusions: The present study shows that men lacked awareness about the concept of vertical transmission of HIV and also the various aspects of prevention of maternal to child transmission of the infection. Their attitude towards testing was positive even though they were not aware of its implications. Media should be used to create awareness and couple counseling and testing should be promoted in all PPTCT centers thereby increasing the male participation in the PPTCT program.
\end{abstract}

Keywords: Attitude, Awareness, HIV testing, Male involvement, PPTCT 


\section{INTRODUCTION}

The adult prevalence of HIV/AIDS is $0.22 \%(0.16-0.30)$ in India with females constituting $42 \%$ of the estimated people living with HIV. ${ }^{1}$ Children account for $7 \%$ of all new infections and parent to child transmission is the second most common route of HIV transmission in India contributing to about $5 \%$ of infections. ${ }^{2,3}$ The services under prevention of parent to child transmission of HIV were initiated in 2002 under NACP-II, which include primary prevention of HIV, avoiding unintended pregnancies in HIV infected women, prevention of transmission from mother to baby and support women and children living with HIV. The PMTCT need in India in the year of 2017 is an important indicator with an estimated 22,677 women with HIV who gave birth and needed ART to prevent transmission to their baby1. Thus maternal to child transmission of HIV can be prevented by effective utilization of all the components of PPTCT services. But all these components of the program involved participation from the male partners. Utilization of PPTCT services by women is not always voluntary and is highly influenced by the society and the men in the family. Being a patriarchal society in which women's decision making in highly influenced by the men, poor knowledge of the PPTCT services and negative attitude towards testing and treatment in men could affect the success of the program. A reasonable knowledge about the HIV epidemic and PPTCT and the available facilities from the government will create a positive attitude among men which will indirectly influence the uptake of services by women.

Literature review showed that this aspect i.e. awareness and attitude regarding PPTCT among Indian men remained unexplored. Therefore the present study was done to study the knowledge regarding HIV and PPTCT among men accompanying their pregnant partner to the antenatal clinic and also to assess their attitude towards testing and treatment for HIV during pregnancy.

\section{METHODS}

This is a cross sectional descriptive institution based study conducted in Sri Manakula Vinayagar Medical College \& Hospital, Puducherry, India, between July 2019 to December 2019 for a period of 6 months.The study participants were men who accompanied their pregnant wife to the antenatal clinic. The PPTCT program is established in this institution under ICTC and HIV testing is done for all pregnant women attending the clinic after pretest counseling.

A pretested, predesigned questionnaire was used as the survey tool to assess the knowledge of men about PPTCT services and also to assess their attitude towards HIV testing during pregnancy. 300 men who were able to understand the local language or English and who consented to participate in the study were administered this questionnaire before undergoing any pretest counseling for HIV testing by a social worker who was trained by the investigators.

The questionnaire had information on socio demographic characteristics and statement on knowledge regarding mode of transmission, prevention measures, knowledge about components of PPTCT services and HIV during pregnancy with options of Yes/No do not know. Attitude regarding testing and treatment during pregnancy and utilization of PPTCT services was assessed using 3 point Likert scale. The collected data was entered in SPSS 21 and analyzed using descriptive statistics. Institutional ethical committee approval was obtained for the study.

\section{RESULTS}

Table 1: Socio demographic data of participants.

\begin{tabular}{|c|c|c|}
\hline Parameters & $\mathrm{N}=300$ & Percentage \\
\hline \multicolumn{3}{|l|}{ Age } \\
\hline $21-30$ & 134 & 44.6 \\
\hline $31-40$ & 150 & 50 \\
\hline $41-50$ & 16 & 5.3 \\
\hline \multicolumn{3}{|l|}{ Wife's Parity } \\
\hline Primi & 96 & 32 \\
\hline Multi & 204 & 68 \\
\hline \multicolumn{3}{|l|}{ Education } \\
\hline Uneducated & 10 & 3.3 \\
\hline School education & 176 & 58.6 \\
\hline Degree holder & 114 & 38 \\
\hline \multicolumn{3}{|l|}{ Occupation } \\
\hline Unemployed & 30 & 10 \\
\hline Laborer & 88 & 29.3 \\
\hline Business & 48 & 16 \\
\hline Employed & 134 & 44.6 \\
\hline \multicolumn{3}{|c|}{ No. of AN visits along with wife } \\
\hline $1-5$ & 262 & 87.3 \\
\hline $6-10$ & 38 & 12.6 \\
\hline \multicolumn{3}{|c|}{ Source of information } \\
\hline Doctors & 108 & 36 \\
\hline Nurses & 22 & 7.3 \\
\hline Friends & 24 & 8 \\
\hline Media & 146 & 48.6 \\
\hline $\begin{array}{l}\text { Are you aware of } \\
\text { an infection } \\
\text { called HIV / } \\
\text { AIDS }\end{array}$ & $\begin{array}{l}\text { Yes } \\
280(93.3 \%)\end{array}$ & $\begin{array}{l}\text { No } \\
20(6.6 \%)\end{array}$ \\
\hline
\end{tabular}

Among 300 participants $94.6 \%$ of the men were in the age group of $21-40$. Only $3.3 \%$ of our participants were uneducated whereas the rest had at least formal education that can help them to obtain information from media like newspaper and books. Around $87.3 \%$ of the men had accompanied their wives to the hospital for 1-5 antenatal visits. Most of them obtained information from the media $(48.6 \%)$ and counseling from doctors was the next common source of information. 
Table 2: Response to statements regarding knowledge of HIV transmission, prevention and PPTCT.

\begin{tabular}{|llll|}
\hline Statements & Correct response & Wrong response & DNK \\
\hline $\begin{array}{l}\text { HIV is a blood born infection and can be diagnosed using } \\
\text { blood test (Yes) }\end{array}$ & $242(94 \%)$ & $4(1.33 \%)$ & $14(4.66 \%)$ \\
\hline $\begin{array}{l}\text { The most common route of transmission is though } \\
\text { unprotected intercourse (Yes) }\end{array}$ & $274(91.3 \%)$ & $12(4 \%)$ & $14(4.6 \%)$ \\
\hline $\begin{array}{l}\text { Using condoms and being faithful to their partner prevents } \\
\text { HIV transmission (Yes) }\end{array}$ & $264(88 \%)$ & $14(4.6 \%)$ & $22(7.3 \%)$ \\
\hline HIV is not transmitted through blood transfusion (No) & $100(33.3 \%)$ & $198(46 \%)$ & $62(20.6 \%)$ \\
\hline $\begin{array}{l}\text { There are drugs available to slow down the progress of } \\
\text { HIV infection (Yes) }\end{array}$ & $202(67.3 \%)$ & $40(16.6 \%)$ & $58(19.3 \%)$ \\
\hline A pregnant lady could be carrying HIV infection (Yes) & $204(68 \%)$ & $42(14 \%)$ & $54(18 \%)$ \\
\hline $\begin{array}{l}\text { HIV positive mother can transmit the infection to her baby } \\
\text { during pregnancy and child birth (Yes) }\end{array}$ & $204(68 \%)$ & $36(12 \%)$ & $60(20 \%)$ \\
\hline $\begin{array}{l}\text { HIV infection is not transmitted to baby by breast feeding } \\
\text { (No) }\end{array}$ & $138(46 \%)$ & $70(23.3 \%)$ & $92(30.6 \%)$ \\
\hline $\begin{array}{l}\text { HIV transmission from mother to baby can be prevented } \\
\text { by giving drugs during pregnancy(Yes) }\end{array}$ & $186(62 \%)$ & $38(12.6 \%)$ & $76(25.3 \%)$ \\
\hline $\begin{array}{l}\text { Vaginal delivery is the best mode of delivery in a HIV } \\
\text { positive mother (No) }\end{array}$ & $146(48.6 \%)$ & $30(10 \%)$ & $124(41.3 \%)$ \\
\hline $\begin{array}{l}\text { Breast feeding is best avoided by a HIV positive mother } \\
\text { (Yes) }\end{array}$ & $158(52.6 \%)$ & $40(13.3 \%)$ & $102(34 \%)$ \\
\hline HIV testing is available is all AN clinics (Yes) & $268(89.3 \%)$ & $6(2 \%)$ & $26(8.6 \%)$ \\
\hline
\end{tabular}

Table 3: Attitude regarding HIV testing among men.

\begin{tabular}{|llll|}
\hline Statements & Positive attitude & $\begin{array}{l}\text { Neither agree } \\
\text { nor disagree }\end{array}$ & Negative attitude \\
\hline $\begin{array}{l}\text { HIV testing during pregnancy is beneficial to } \\
\text { mother and baby }\end{array}$ & $284(94.6 \%)$ & $8(2.6 \%)$ & $8(2.6 \%)$ \\
\hline $\begin{array}{l}\text { All pregnant women should undergo HIV testing } \\
\text { during pregnancy }\end{array}$ & $278(92.6 \%)$ & $16(5.3 \%)$ & $6(2 \%)$ \\
\hline $\begin{array}{l}\text { HIV testing should be done for both husband and } \\
\text { wife simultaneously }\end{array}$ & $268(89.3 \%)$ & $24(8 \%)$ & $8(2.6 \%)$ \\
\hline $\begin{array}{l}\text { Pregnant women can be tested for HIV without } \\
\text { husband's permission }\end{array}$ & $240(80 \%)$ & $30(10 \%)$ & $30(10 \%)$ \\
\hline $\begin{array}{l}\text { Information about MTCT of HIV should be given } \\
\text { simultaneously to husband and wife }\end{array}$ & $248(82.6 \%)$ & $38(12.6 \%)$ & $14(4.6 \%)$ \\
\hline $\begin{array}{l}\text { Undergoing HIV test when your wife is pregnant } \\
\text { can be stressful to man }\end{array}$ & $74(24.6 \%)$ & $106(35.3 \%)$ & $120(40 \%)$ \\
\hline $\begin{array}{l}\text { Are you prepared to undergo HIV testing along } \\
\text { with your wife }\end{array}$ & Yes: $266(88.6 \%)$ & - & No: $34(11.3 \%)$ \\
\hline
\end{tabular}

Most of the men participating in the study (93.3\%) had a formal knowledge about HIV infection. Only $6.6 \%$ of them said that they were not aware of the entity (Table 1).

Knowledge regarding the common route of transmission of HIV and availability of blood test to diagnose the condition was fairly good among participants. But only $33.3 \%$ of the participants were aware that unsafe blood transfusion could be a route of transmission. About $88 \%$ of the participants were aware that condoms help in prevention of transmission of the disease.
Knowledge about mother to child transmission was generally poor among participants. Only $68 \%$ were aware that a HIV positive mother could transmit infection to her baby and more than half of the participants were not aware that breast feeding could be a source of infection. Only $32.6 \%$ considered that breast feeding should be avoided by a HIV positive mother. Among our participants, $67.3 \%$ were aware that drugs were available to treat HIV infection but $39 \%$ of the participants were not aware that mother to child transmission can be curtailed by giving ART during pregnancy majority of 
the participants were aware that HIV testing is done in all antenatal clinics (Table 2).

Attitude towards HIV testing for the mother during pregnancy was good with $94.6 \%$ of the participants considering that HIV testing during pregnancy is beneficial to mother and baby. When it came to practice, $92.6 \%$ agreed that all pregnant women should undergo HIV testing during pregnancy and $80 \%$ of the participants agreed that women can be tested without husband's permission. Most of them $(82.6 \%)$ agreed that information regarding PPTCT should be given simultaneously to both partners and $89.3 \%$ agreed that both should undergo testing simultaneously. Almost one fourth of the study participants felt that undergoing HIV test on themselves when their wife was pregnant will be stressful. Acceptance for HIV testing was fairly good even before pre-test counseling to the extent of $88.6 \%$ of the participants whereas $11.3 \%$ were not willing to get tested (Table 3).

Among the participants who did not want to get tested for HIV, 52.9\% assumed that their HIV status will be the same as that of their wife whereas $29.4 \%$ said that they were not comfortable undergoing the test along with their wife (Table 4).

Table 4: Reasons cited by men for avoiding HIV testing.

\begin{tabular}{|ll|}
\hline I don't know the importance of testing & $\mathbf{2 ( 5 . 8 \% )}$ \\
$\begin{array}{l}\text { I am not comfortable undergoing the } \\
\text { test along with my wife }\end{array}$ & $10(29.4 \%)$ \\
\hline I don't want to know my status & $4(11.7 \%)$ \\
\hline $\begin{array}{l}\text { My HIV status will be the same as } \\
\text { that of my wife }\end{array}$ & $18(52.9 \%)$ \\
\hline
\end{tabular}

\section{DISCUSSION}

In the present study, we found that women were frequently accompanied by their husband when they came for antenatal checkup and most of these men had a formal knowledge about HIV infection. The main source of information to these men was found to be the media followed by medical personnel which was similar to a study from Delhi by Kumar et al. ${ }^{4}$

In the present study we found that acceptance to HIV testing during antenatal visit was good (88.6\%) among the participants even before pretest counseling. Contrary to our study, a study from Maharashtra by Shiradkar et al showed a poor attendance to PPTCT clinic and reluctance to get tested for HIV among men who attended their antenatal clinic. ${ }^{5}$

Another Indian study revealed that only $30 \%$ of men with HIV negative wife got tested in spite of pretest counseling which shows that they consider PPTCT is only for HIV positive patients. ${ }^{4}$ Katz et al reported that $95 \%$ of men attending antenatal clinic with wife accepted
HIV testing which was similar to our study. ${ }^{6}$ A study from Ethiopia found that only $20 \%$ of pregnant women were accompanied by male partner to antenatal services but among them $82 \%$ have had HIV counseling and testing. ${ }^{7}$

Studies have shown that knowledge about the route of transmission of HIV and about testing facilities increased the willingness to get tested among male partners. ${ }^{8}$ In our study we found that knowledge about sexual transmission was good $(91.3 \%)$ and a large number of them were aware $(88 \%)$ that condoms will prevent transmission. About $89.3 \%$ were also aware that HIV testing is available in conjunction with antenatal services.

Studies have found that men who are aware of PMTCT were more likely to get involved as they perceive the benefits of testing to themselves and their new born. ${ }^{9}$ Awareness about the importance of testing and about available services increased participation in PMTCT by at least 2 times. $^{10}$

In the present study we found that awareness about various components of PPTCT was poor. Only $68 \%$ of the participants were aware that a HIV positive mother could transmit HIV infection to her newborn baby. Awareness about breast feeding as a source of infection was present only in $46 \%$ of the participants and $48.6 \%$ were only aware that vaginal delivery could increase the risk if transmission to the baby.

Zenebe et al in their study reported that $57.6 \%$ of men were aware that breast feeding should be avoided to prevent transmission of HIV from mother to baby but only $3.4 \%$ were aware that caesarean section can reduce the transmission. ${ }^{11}$

A similar study done in Cameroon showed that $81 \%$ of men had heard about PMTCT, 74.2\% were aware that breast feeding increased transmission and $31.5 \%$ of their study subjects were aware that cesarean section reduced the rate of transmission. Majority of participants had a positive attitude towards PMTCT in this study in which awareness was good. ${ }^{12}$

In the present study only $41 \%$ of the participants were aware ART to HIV positive mother can reduce the risk of transmission to her baby compared to a study done in Cameroon in which $69.8 \%$ had awareness about ART. ${ }^{13}$ In another study awareness about ART reducing transmission was $78.8 \% .^{12}$

In the present study, we found men had a positive attitude towards testing and only $11.4 \%$ were not willing to undergo testing along with their partners. The most common reason cited was that their status would be the same as that of the wife and $29.4 \%$ of the men were not comfortable to undergo testing along with their wife. Many studies have revealed several reasons most of them being related to socio cultural and health system. Morfaw 
et al found that the common reasons were reluctance to know their status and lack of time to accompany their wife. $^{14}$

Other reasons were similar to our study in which pregnancy is considered a woman's affair and assuming that their status will be the same as their partner. Most of the men believed that their HIV status will be the same as their wife and also that prevention of mother to child transmission was mother's responsibility. ${ }^{15,16}$

Other common reasons were lack of awareness, economical and negative staff attitude. ${ }^{13,17}$ Stigma and fear of disclosure were also significant barriers to male involvement. ${ }^{18}$ Some studies have cited literary and religious beliefs as factors hindering HIV testing. ${ }^{19} \mathrm{~A}$ significant perceived barrier to testing was that PMTCT was a women-child affair that did not require any male participantion. ${ }^{20}$

Our study participants cited that testing simultaneously for both partners was stressful to them. On the contrary studies have shown that acceptance to counseling and testing will increase if tested simultaneously with their partners. ${ }^{21}$ Studies have indicated that couple testing and counseling resulted in decreased unprotected sex and increase in partner disclosure. This study also encouraged couple counseling and testing even outside antenatal settings which are male friendly. ${ }^{22}$

\section{CONCLUSION}

The present study shows that men accompanying their pregnant wife had good awareness about route of transmission of HIV and its prevention through usage of condoms but lacked awareness about the concept of vertical transmission of HIV from mother to baby and also the various aspects of prevention of maternal to child transmission of the infection. Their attitude towards testing was positive even though they were not aware of its implications. We found that media was the main source of information to them. So this route can be used to create more awareness regarding prevention of vertical transmission of HIV so that they understand the implications of HIV testing during pregnancy. Community sensitization is essential to promote a positive attitude towards PPTCT. Couple counseling and testing should be promoted in all PPTCT centers thereby increasing the male participation. Active involvement of men in counseling and testing will indirectly increase uptake of PPTCT services by women as they grossly influence decision making in women in countries like India.

\section{Limitations}

This is a hospital-based study in a small group whereas a community based qualitative approach will yield more information regarding attitude towards HIV testing among men.
Funding: No funding sources

Conflict of interest: None declared

Ethical approval: The study was approved by the Institutional Ethics Committee

\section{REFERENCES}

1. National AIDS Control Organization \& ICMRNational institute of Medical statistics (2018). HIV estimations 2017: Technical report. New Delhi: NACO, Ministry of Health and Family welfare, Government of India.

2. NACO Annual report; 2012-13. Available from http://www.naco.gov.in/upload/publication/Annual \% 20 Report/ Annual \% 20 report \% 20 2012-13 English. pdf.

3. National AIDS control organization. Annual Report 2010-11. New Delhi, India: Department of AIDS control, Ministry of Health and family welfare, Govt of Ind. 2012.

4. Kumar A, Singh B, Kusuma YS. Counseling services in prevention of PMTCT in Delhi, India: An assessment through a modified version of UNICEFPPTCT tool, J Epid Glob Health. 2015;5(1):3-13.

5. Shiradkar S, Mande S, Bapat G, Setia MS. Is it time to bring the parent into the prevention of parent to child transmission programs in India? A Study of trends over a 10 year period in a prevention of parent to child transmission clinic in India. Ind $\mathrm{J}$ Sex Transm Dis. 2016;37(1):58-64.

6. Katz DA, Kiarie JN, John-Stewart GC, Richardson BA, John FN, Farquhar C. Male perspectives on incorporating men into Antenatal HIV counseling and Testing. PLoS ONE. 2009;4(11):e7602.

7. Haile and Brhan. Male partner involvement is PMTCT: a cross sectional study, Mekelle. Northern Ethiopia. BMC pregnancy and child birth. 2014;14(1):65

8. Das, A, Babu GR, Ghosh P, Mahapatra T, Malmgren R, Detels R. Epidemiologic correlates of willingness to be tested for HIV and prior testing among married men in India. Int J STD AIDS. 2013;24(12):957-68.

9. Amano A, Musa A. Male involvement in PMTCT and associated factors among men whom their wives had AN visit 12 months prior to the study in Gondar Town, North west Ethiopia, Pan Afr Med J. 2016;24(1):239.

10. Byamugisha R, Tumwine JK, Semiyaga N, Tylleskär T. Determinants of male involvement in the prevention of mother to child transmission of HIV programme in Eastern Uganda: a cross sectional survey. Repr Health. 2010;7(1):12.

11. Zenebe A, Gebeyehu A, Derseh L, Ahamed KY. Male partner involvement in HIV counseling and testing and associated factors among partners of pregnant woman in Gondar Town, Northwest Ethiopia. J Preg. 2016(2);1-6

12. Nsagha D, Halle-Ekane G, Nfor C, Ngowe M, Nasah $\mathrm{B}$. The role of the male partner in the prevention of 
mother to child transmission of HIV in Cameroon. Am J Epidem and inf Dis. 2014;2(2):52-9.

13. Nkuoh GN, Meyer DJ, Tih PM , Nkfusai J. Barriers to men's participation in antenatal and prevention of mother to child HIV transmission care in Cameroon. Africa J Midwifery Womens Health. 2010;55(4):363-9.

14. Morfow F, Mbuagbaw L, Thabane L, Rodringues C, Wunderlich AP, Nana P, et al. Male involvement in prevention programmes of mother to child transmission of HIV : A systematic review to identify barriers and facilitators Syst Rev. 2013;2(1):5.

15. Falnes EF, Moland KM, Tylleskar T, De Paoli M, Msuya SE, Engebretsen IM. "It is her responsibility"; Partner involvement in prevention of MTCT of HIV programmes, Northern Tanzania. J Int AIDS Society. 2011;14(1):1-2.

16. Koo K, Makin J, Forsyth BW. Barriers to male participation in programs to prevent MTCT in South Africa. AIDS Edu and Prevent. 2013;25(1):14-24.

17. Kebaabetswe PM. Barriers to participation in prevention of mother to child transmission program in Gaborone, Botswana a qualitative approach. AIDS Care. 2007;19(3):355-60.
18. Osoti A, Han H, Kinuthia J, Farquhar C. Role of male partner in the prevention of mother to child HIV transmission. Res and Rep in Neonat. 2014;4:131-8.

19. O'Gorman DA, Nyirenda LJ, Theobald SJ. Prevention of MTCT of HIV infection: Views and perceptions about swallowing nevirapine in rural Lilongwe, Malawi, BMC Public Health. 2010;10(1):354-361.

20. Njunga J, Blystad A. The drone program : gendered experiences of HIV positive mothers enrolled in PMTCT programs the case of rural Malawi, Int Breast feeding J. 2010:5(1):14-9.

21. Okonkwo KC, Reich K, Alabi AI , Umeike N, Nachman SA. An evaluation of awareness: Attitudes and beliefs of pregnant Nigerian women towards voluntary counseling and testing for HIV, AIDS Patient Care and STDs. 2007;21(4):252-60.

22. Chigbu B, Onwere S. How do we improve male partner involvement in prevention of MTCT of HIV in Nigeria? Trop $\mathrm{J}$ Obstet and Gynaec. 2016;33(1):37-43.

Cite this article as: Krishnamoorthy N, Navis FS Attitude to counseling and testing for HIV and knowledge about prevention of mother to child transmission of HIV in men accompanying antenatal attendees at a tertiary care hospital in South India. Int $\mathbf{J}$ Reprod Contracept Obstet Gynecol 2021;10:1883-8. 